\title{
Abortion in Ghana: Legal or Illegal? An Observation at the Abura Dunkwa District Hospital
}

\author{
Bill K. Anaba ${ }^{1,2,3 *}$ Song Wei Qi ${ }^{2} \quad$ Bao Ke Yong ${ }^{2} \quad$ Michael G. Danso ${ }^{3}$ \\ 1.College of Clinical Medicine, Inner Mongolia University for the Nationalities, 536 \\ West Huo Lin He Street, Horqin District, Tongliao City, Inner Mongolia, China PR. \\ 2.Affiliated Hospital of Inner Mongolia University for the Nationalities, 1742 Huo Lin \\ He Street, Horqin District, Tongliao City, Inner Mongolia, China PR. \\ 3.Ghana Health Service, Abura Dunkwa District hospital, P.O. Box 55, Abura Dunkwa, Ghana
}

\section{Conflict of interest: *Pro-Life}

\section{Abstract}

Background: Elective abortion with its medico-legal controversies is a major worldwide debatable topic. The question whether to legalize abortion or not continues to be a contentious affair. The public interest nature of this debate has led to the emergence of two advocacy groups: Pro-Life and Pro-Choice. The former argues that the unborn fetus is human with life. The latter strongly postulates that women should have choices of what happens to their body. Whilst this debate lingers on, we decided to do a four month clinical observation of the reality on the ground in Ghana's Abura Dunkwa Ditrict Hospital. Methods: This was a clinical observational study. It covered a four month clinical management of abortion related patients at the Abura Dunkwa district hospital of Ghana. History of presenting complaints and social/ family histories were particularly noted in details. We then compared our observation against abortion laws around the world and Ghana in particular. Findings: we observed that the lack of publicity and agreed interpretation of Ghana's abortion laws have resulted in criminal abortions leading to complications such as incomplete abortion, hemorrhage, sepsis, etc. We also discovered that many criminal abortions in fact met Ghana's abortion Acts' 'exceptions for termination of pregnancy'Conclusion: Ghana's abortion Acts though do not make abortion legal, the laws have permitted enough grounds for justifiable terminations of pregnancies, yet ignorance of the law has led to women's continued engagement in criminal and unsafe abortions leading to severe morbidities and mortalities

Keywords: Abortifacients, hemorrhage, sepsis, morbidity, mental health, adjustment disorder

DOI: $10.7176 / \mathrm{JHMN} / 61-02$

Publication date: April $30^{\text {th }} 2019$

\section{INTRODUCTION}

One outstanding feature of human civilization is the enactment of laws and legislations to regulate, control and promote the behavior and activities of people.

Conscience, human values, morality and religious orientation impact greatly on laws made by governments all over the world. In formulating, enacting and passing laws, law makers get challenged with religious and moral values that some countries would rather adopt religious commands as its national laws.

One universal law of the world is the law 'not to kill another person'. The courage to kill a human being is overwhelmingly inhibited by conscience and human values that even some countries whose judicial system sentences culprits of serious crimes to death end up either commuting it to life sentence or granting a pardon.

If this universal acceptance not to take another's life is undisputed, then the question is where and when do humans start having life?

The curiosity to get answers for this question forces one to return to the uterus and ask some questions.

Is elective abortion a murder? Is abortion legal or illegal in Ghana? What specific laws exist regarding abortions in Ghana? What is the reality on the ground? Our observation at the Abura Dunkwa District Hospital of Ghana is shared in this study.

\section{BACKGROUND}

\section{Abortion}

The termination of pregnancy before viability, mostly before $24^{\text {th }}$ to $28^{\text {th }}$ week gestation and a fetal weight of less than 1000 grams is a common worldwide definition for abortion. Technically, if the termination occurs spontaneously, it is euphemistically called Miscarriage. On the other hand, if the termination was actively initiated by way of chemical/pharmaceutical agent or mechanical or surgical technique then it becomes an Induced abortion.

Under some challenging health grounds, abortions are induced to save the life of the mother or on the grounds of a fetus with developmental impairments incompatible with life. This procedure then becomes Therapeutic Abortion.

An abortion that is not consistent with statutory provisions whether performed by a qualified personnel or a 
quack abortionist is Criminal Abortion.

If it was initiated and carried out by quack and unqualified person or in an environment that lacks the medical standards it is referred to as an Unsafe Abortion.

Quite often, abortions, especially criminal and unsafe abortions run into complications, most commonly infections, in this situation it becomes a Septic Abortion. Abortions done in accordance with statutory laws by qualified medical personnel in an accredited standard facility are called Safe Abortion. Finally, some pregnant women may request for termination of pregnancy without any maternal or fetal, socio-cultural and legal reasons. This termination is called Elective Abortion. Abortion in this article is used synonymously with elective abortion.

Abortion may also be classified according to two time periods: Early abortion: Occuring before 12 weeks of gestation. Late abortion: occurs 12-24-27 weeks of gestation.

\section{Abortion Controversies in Ghana.}

Just like many other countries around the world, abortion is a highly contentious personal and public topic. Ghanaians, like many developing countries are highly religious and spiritual. Hardly will people make an open advocacy for legalization of abortion in public. All overwhelming majority of Ghanaians are openly against abortion. However, hardly does a day pass without women-teenagers, students, middle age and peri-menopasal women trooping into hospitals with incomplete abortions which they usually claim wasn't induced.

The reasons for this hide and seek affair is not farfetched. The Ghana Statistical Service (GSS), Ghana Health Service (GHS) and Macro International, Ghana Maternal Health Survey 2007 revealed the main reasons Ghanaian women opt for termination of their pregnancies albeit they openly argue against legalization of abortion.

The major reasons for abortion according to the survey were lack of money to take care of baby if born. The desire to delay childbearing, the need to continue education, the need to continue work, lack of love for the man, not ready for marriage, the need for child spacing and partner refusing responsibility of the pregnancy.

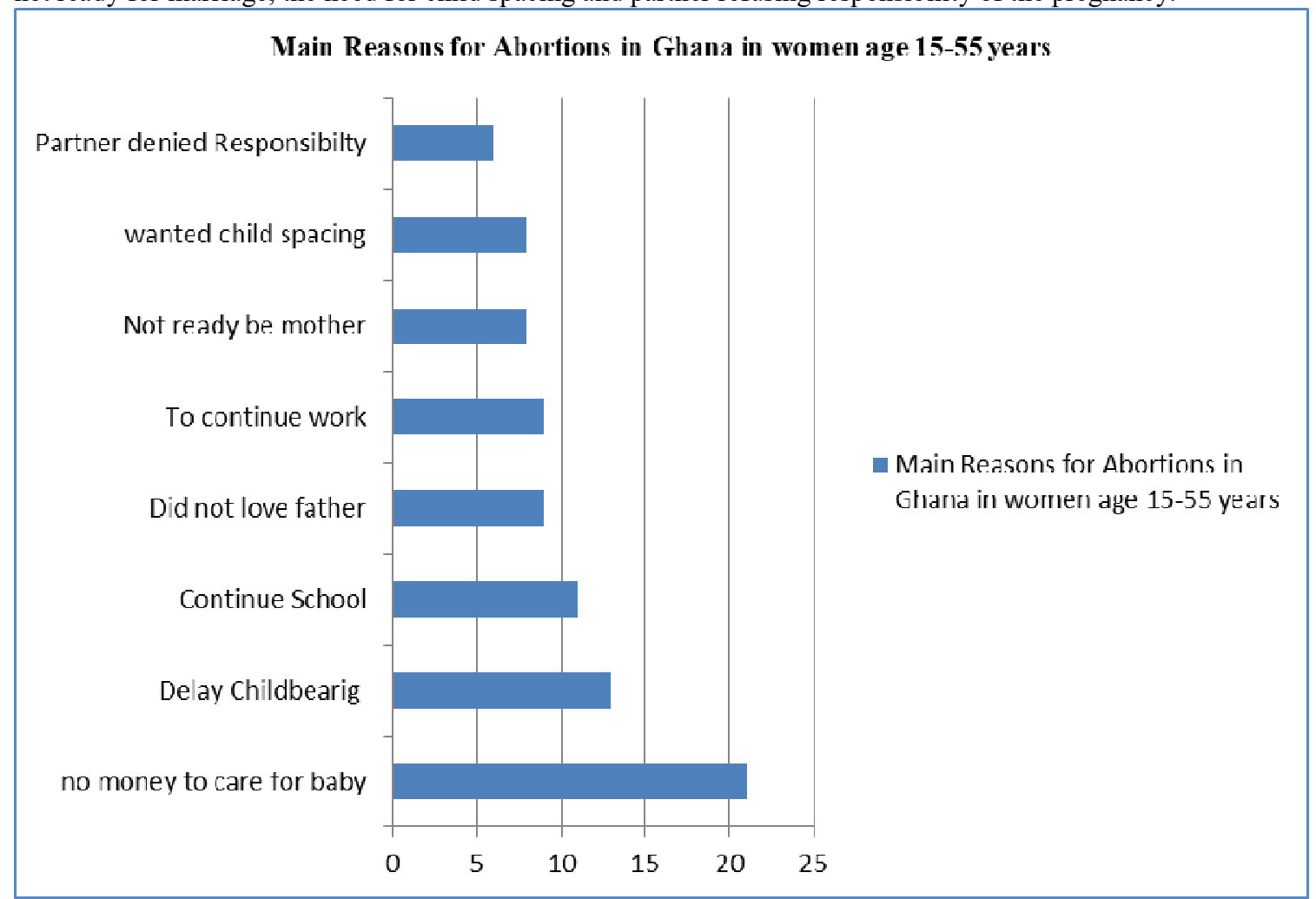

Figure 1: MAIN REASONS FOR ABORTION IN GHANA

Modified from Ghana Statistical Service (GSS), Ghana Health Service (GHS) and Macro International, Ghana Maternal Health Survey 2007.

\section{THE GHANA'S ABORTION LAW}

The first legal Act in Ghana regulating abortion was passed in 1960, Act 29, section 58 of the 1960 Criminal code. This Act was amended by PNDCL 102 of 1985 which maintained all provisions of the previous Act and added 'Causing Harm to Child at Birth and Concealment of Birth' as new provisions 
CRIMINAL OFFENCES ACT - 1960 (ACT 29)

Section - 58 - Abortion or Miscarriage

(1) Subject to the provisions of subsection (2) of this section-

(a) any woman who with intent to cause abortion or miscarriage administers to herself or consents to be administered to her any poison, drug or other noxious thing or uses any instrument or other means whatsoever; or

(b) any person who-

(i) administers to a woman any poison, drug or other noxious thing or uses any instrument or any other means whatsoever with the intent to cause abortion or miscarriage, whether or not that the woman is pregnant or has given her consent;

(ii) induces a woman to cause or consent to causing abortion or miscarriage;

(iii) aids and abets a woman to cause abortion or miscarriage;

(iv) attempts to cause abortion or miscarriage; or

(v) supplies or procures any poison, drug, instrument or other thing knowing that it is intended to be used or employed to cause abortion or miscarriage,

shall be guilty of an offence and liable on conviction to imprisonment for a term not exceeding five years.

(2)

It is not an offence under subsection (1) of this section if an abortion or a miscarriage is caused in any of the following circumstances by a registered medical practitioner specialising in gynaecology or any other registered medical practitioner in a Government hospital or in a private hospital or clinic registered under the Private Hospitals and Maternity Homes Act, 1958 (No. 9) or in a place approved for the purpose by legislative instrument made by the Secretary:

(a) where the pregnancy is the result of rape, defilement of a female idiot or incest and the abortion or miscarriage is requested by the victim or her next of kin or the person in loco parentis, if she lacks the capacity to make such request;

(b) where the continuance of the pregnancy would involve risk to the life of the pregnant woman or injury to her physical or mental health and such woman consents to it or if she lacks the capacity to give such consent it is given on her behalf by her next of kin or the person in loco parentis; or (c) where there is substantial risk that if the child were born, it may suffer from, or later develop, a serious physical abnormality or disease.

(3) For purposes of this section "abortion or miscarriage" means the premature expulsion or removal of conception from the uterus or womb before the period of gestation is completed.

\section{Commentary on the Abortion Act:}

Like many other countries, abortion is both legal and illegal depending on the indications, setting and personnel carrying out the procedure. Therapeutic and other 'good-reasons' abortions are legal provided they are performed by qualified personnel in accredited facility. On the other hand, the Act does not only strictly outlaw Elective, criminal and unsafe abortions but also prescribes an imprisonment term not exceeding five years for culprits.

The Act further extends its tentacles to cover people who aid and abet in, lure, supply abortifacient substance and attempt abortions as infringers of the abortion law.

Again, under this Act, whilst rape is a good reason for abortion, same cannot be said of Defilement, defined as a consensual sexual intercourse with someone younger than 16 years old, unless she doubles as a mentally ill person described colloquially as 'female idiot' in this Act.

Moreover, the mention of mental health under the Act gives Pro-Choice groups concrete reason to jubilate. Abortion may be permitted where 'continuance of the pregnancy would involve risk to the life of the pregnant woman or injury to her physical or mental health and such woman consents to it.

According to American Psychiatric Association's DSM-IV, a mental disorder is a psychological syndrome or pattern which is associated with distress (e.g. via a painful symptom), disability (impairment in one or more important areas of functioning), increased risk of death, or causes a significant loss of autonomy.

The WHO's International Classification of Diseases, ICD-10, states that mental disorder is "not an exact term", although is generally used "...to imply the existence of a clinically recognizable set of symptoms or behaviors associated in most cases with distress and with interference with personal functions." (WHO, 1992). These definitions of mental health can be interpreted to justify a large chunk of elective abortions.

Finally, another interesting deduction from the Act is the fact that pharmacists and licensed chemical sellers who supply abortifacients to abortionists are all on the wrong side of the law. Similarly, family members, friends and people who coerce and lure women to do abortions are all violators of Ghana's abortion law. 


\section{METHODS}

In a four month study period in a busy district hospital where late stage complicated obstetric and gynecological cases troop in nonstop, particular attention was paid to abortion related cases. The social, obstetric and gynecological histories of patients were especially taken in details. History and course of presenting complaints were accurately documented.

We then reviewed literature from a wide range of sources against our observations. Abortion laws around the world with special emphasis on that of Ghana

\section{RESULTS}

We observed that the majority of abortions were admitted on accounts of severe complications following criminal induction. The usual norm was for patients to claim they were pregnant and started bleeding spontaneously. When challenged to say the truth to make treatment easier they would admit having taken an abortifacient or having undergone an attempted evacuation of the uterus under the hands of a quack abortionist. They will neither tell where nor who this person is.

Analysis of the age group of presenting cases indicates that attempted abortions were more common in people who were most likely not to want pregnancy. Junior/senior high school Teenage girls and grand multiparous women were mostly involved.

One most striking observation that ran through all encountered cases was late presentation with severe complications. Two most common complications that sent doctors, midwives/nurses and laboratory technicians running were hemorrhage and septic shocks. Incomplete induced abortions complicated with immediate or late intractable hemorrhage was a common diagnosis. In some cases, patients wittedly took the abortifacients then quickly rushed to hospital claiming they were pregnant and having spontaneous bleeding per vaginum. When stabilized and discharged with intact pregnancy to start ANC they only go to repeat the abortion process even in increased dosage. The diagram below indicates the main complications encountered in our observation.

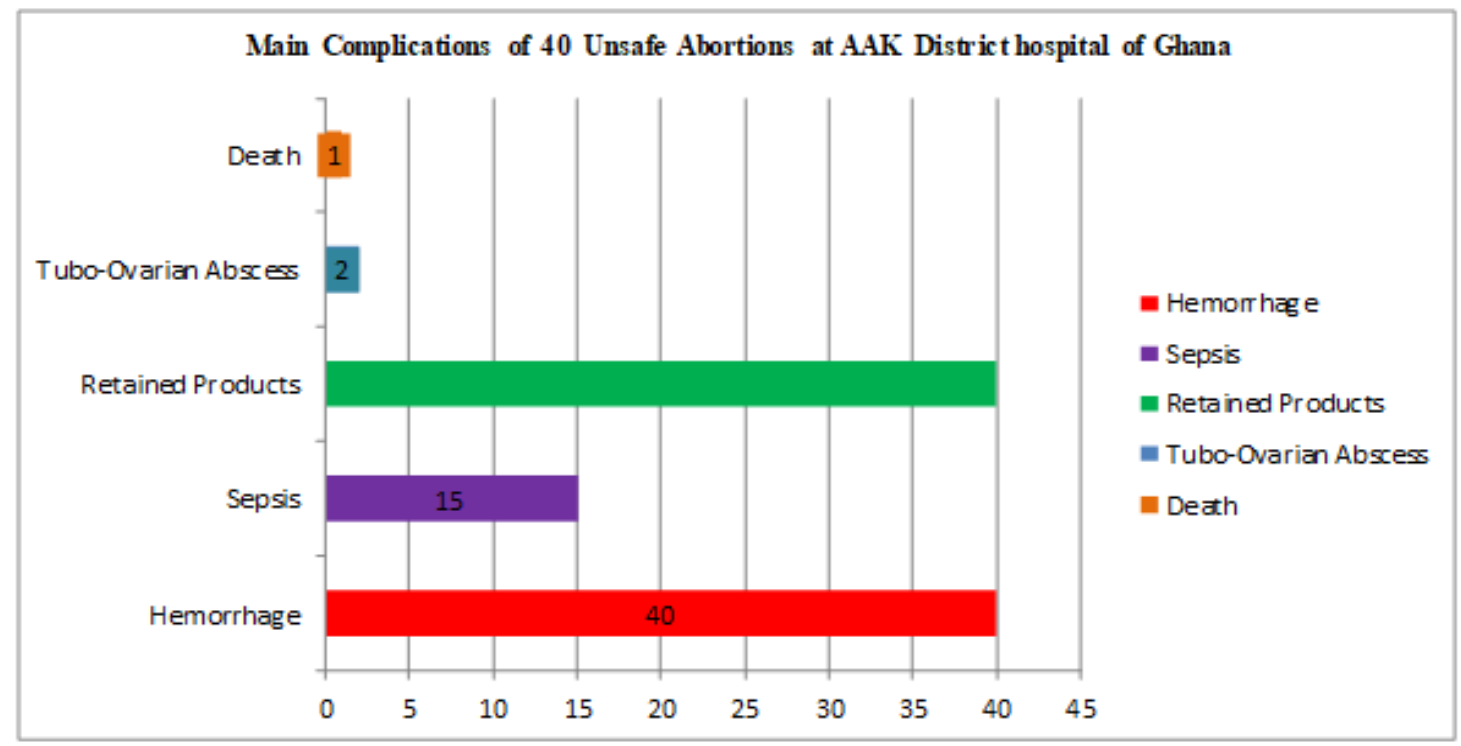

Fig. 2: Main complications of 40 unsafe abortions at Abura Dunkwa district hospital of Ghana from October 2017 to January 2018.

All patients presented with retained products of conceptions plus bleeding. Sepsis and septic shock occurred in 15 out of 40 cases. Two women suffered severe morbidity on account of PID and Tubo-Ovarian Abscess (TOA). One woman lost her life.

Another observation was that patients whose history indicated that they initially requested for abortions on account of not ready or not wanting the pregnancy and were denied by medical staff on grounds of illegality and moral values returned few days later with threatened or incomplete abortions which they would usually claim started spontaneously. This is worth mentioning, in that, it tells us when people are refused safe abortions they will resort to unsafe criminal terminations and the complications will come back on our heads!

The diagram below shows the methods employed by patients to terminate their pregnancies prior to reporting to Abura Dunkwa District Hospital for treatment from October 2017 to January 2018. 


\section{Methods/Procedures used for unsafe abortions by patients who reported at AAK}

\section{District hospital}

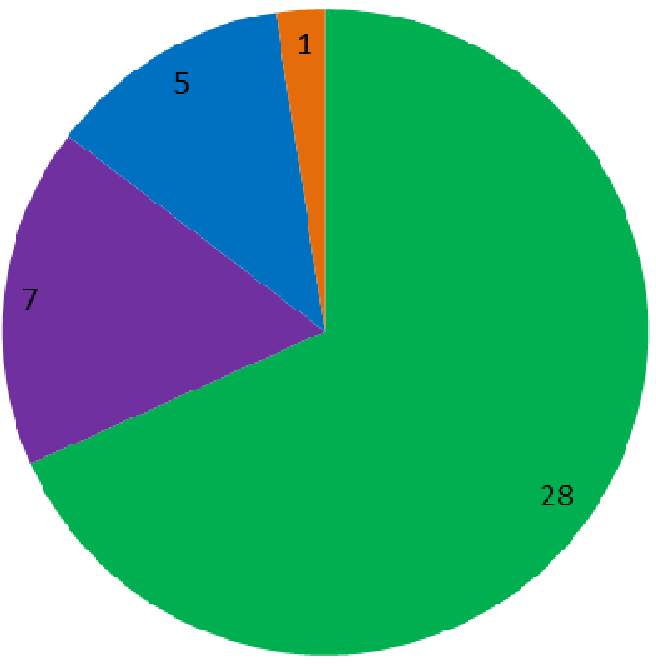

Tablet trom drugstore

- Herbal concoction

Mixture of sugar/soft drinks

Attempted D\&C

Figure 3: Methods and Procedures used by 40 patients to induce abortions prior to reporting at Abura Dunkwa district hospital of Ghana from October 2017 to January 2018.

Most of the studied patients bought Abortifacients from drugstores. Cytotec is a well known term in this business. The second method was traditional mixture of drinks and sugar, followed by usage of herbs. One case admitted she underwent attempted Dilatation and curettage in someone's room.

\section{DISCUSSION}

Recent debates on whether abortion is legal should be climaxed to bring awareness on the law. Some analysts who also postulate that the law leaves medico-legal practitioners in dilemma should be encouraged to push for opening discussion and awareness of the abortion laws.

Some authors also claim, for instance, that there is dilemma the clause' abortion may be permitted where the continuance of the pregnancy would involve risk to the life or physical and mental health of the pregnant woman. We think this should not a problem as far clinical practice is concerned.

Pregnancy is a physiological state during which all changes must be within normal range for pregnancy. Naturally, this normal pregnancy physiology does not put the woman's life or health at risk and it would be unheard of for a qualified medical practitioner to start wondering if he/she should carry out a pregnancy termination only because he/she thinks pregnancy is a risk to health.

All clinicians without any ulterior motif know exactly what this clause is talking about and would readily advise pregnancy termination if they come across it. In short, if a woman's pregnancy normal-physiology deranges pathologically and is clinically proven by way of physical, laboratory or imaging tests then this woman meets the criteria for pregnancy termination on grounds of risk to her health and life. I have no doubt all obstetrician gynecologists and other clinicians involved in management of pregnancy know this as a matter of fact.

Some analysts go further to also argue that mental health is too subjective and that the clinician has no way of disproving patients who decide to play the mental health factor. An Obstetrician Gynecologist, Dr Michael G. Danso is one of those opposed to elective abortions but he thinks "of course one can always find a way out of the law to perform abortion but I don't do it because of my own religious and psychological concerns". This argument is genuine and highly indispensable considering the fact that most unwanted pregnancies come with enormous economic, social and physical stress which one can easily capitalize on as enough threat to mental health with a comfortable backing of the ICD-10 and DSM-IV classifications of mental disorders.

Pregnancy itself as a biological change hardly deranges mental health. Our observation is that the 'wantness' or 'unwantness', and readiness and unreadiness coupled with physical, economic and social supports available are the deciding factors of mental health of the pregnant women. Most women seeking pregnancy termination clearly have a bad socio-economic background. 


\section{CONCLUSION}

Ghana's abortion Acts though do not make abortion legal, the laws have permitted enough grounds for justifiable terminations of pregnancies, yet ignorance of the law has let to women continued engagement in criminal and unsafe abortions leading to severe morbidities and mortalities.

\section{RECOMMENDATION}

We recommend that government amends the abortion Act to make it an optional personal decision affair for both doctors and patients. Those who think it's against their morality, religious and spiritual principles will have the option of not engaging in it. Those who want to engage in it based on justifiable reasons would have the option to do so too. We hope this will cure the hypocrisy and double standard of doing what we are against.

\section{ACKNOWLEDGEMENT:}

The author sincerely appreciates and acknowledges the following personalities for their unconditional contribution, direction, supervision and editorial support:

1. Prof. Dr. Song wei Qi and Associate Professor Dr. Bao Ke Yong, my supervising Professor and Assistant Supervisor respectively.

2. Dr Michael G. Danso, senior specialist and medical superintendent of Abura Dunkwa District hospital of Ghana.

\section{REFERENCES:}

(1) Ghana Statistical Service (GSS), Ghana Health Service (GHS) and Macro International, Ghana Maternal Health Survey 2007, Accra,Ghana: GSS and GHS; and Calverton, MD, MD, USA: Macro International, 2009.

(2) WHO, Safe Abortion: Technical and Policy Guidance for Health Systems, Geneva: WHO, 2003.

(3) Moore, K. L.; T. V. M. Persaud (2003). The Developing Human: Clinically Oriented Embryology. W. B. Saunders Company. ISBN 0-7216-6974-3.

(4) Allery, J. P.; Telmon, N.; Mieusset, R.; Blanc, A.; Rougé, D. (2001). "Cytological detection of spermatozoa: Comparison of three staining methods". Journal of forensic sciences. 46(2): 349-351

(5) Morhe ESK, Morhe RAS and Danso KA, Attitudes of doctors toward establishing safe abortion units in Ghana, International Journal of Gynecology and Obstetrics, 2007, 98(1):70-74.

(6) Center for Reproductive Rights, The world's abortion law, 2014 updates, http://worldabortionlaws.com/.

(7) Center for Reproductive Rights, "The World's Abortion Laws Map 2013 Update," June 2013

(8) Cook RJ, Dickens BM, Bliss LE. International developments in abortion laws from 1988 to 1998. Am J of Pub Hlth1999; 89(4) : 579586.

(9) Abortion or miscarriage. Consolidation of Criminal Code of Ghana, 1960. Act 29. Sec-tion 58, $10^{\text {th }}$ December 1999; 37-38.

(10) FIGO. Ethical Guidelines Regarding Induced Abortion for Non- Medical Reasons. Septem-ber, 2002 .

(11) Adanu RMK, and Tweneboah E. reasons fears and emotions behind induced abortions in Ac-cra, Ghana. Research Review NS 20.2 (2004); 1-9.

(12) Ampofo DA. The dynamics of induced abor-tions and the social implications for Ghana. Ghana Med $J$ Dec. 1970: 295- 302.

(13) World Health Organization, Safe abortion: Technical and policy guidance for health systems (Geneva: WHO, 2012).

(14) Guttmacher Institute, Induced abortion worldwide: Global incidence and trends (May 2016). Available at https://www.guttmacher.org/fact-sheet/induced-abortion-worldwide.

(15) Guttmacher Institute, Unsafe Abortion a Major Cause of Maternal Death in Ghana, 2018, https://www.guttmacher.org/print/news-release/2010/unsafe-abortion-major-cause-maternal-death-ghana

(16) Abortion Liberalization in World Society, 1960-2009, AJS. 2015 November ; 121(3): 882-913.

(17) Republic Of Ghana. Criminal Offences Act - 1960 (Act 29) Section 58 ,Ghana Legal, available on http://laws.ghanalegal.com/.

(18) Republic Of Ghana. Criminal code (Ammendment Law), PNDC Law 102(1985), Ghana Legal, available on http://laws.ghanalegal.com/.

(19) Aboagye B and Akosa AB. An autopsy of maternal deaths. Ghana Med J 2000; 34: 152-156.

(20) Morhe ESK. Views of doctors on institution-alization of termination of pregnancy in Ghana. Long commentary for FWACS part II examinations. 2006; 281-294.

(21) Abortion Rights Coalition of Canada, "Abortion Law and Policy: Comparisons Between the U.S. and Canada," Feb. 2006

(22) Guttmacher Institute, "State Policies in Brief: An Overview of Abortion Laws," Aug. 1, 2013

(23) Reproductive Health Matters, "Second Trimester Abortion Laws Globally: Actuality, Trends and Recommendations," 2010 
(24) Understand the issues. Understand each other, ProCon.org, 2018, https://www.procon.org/

(25) American Psychiatric Association. Diagnostic and Statistical Manual of Mental Disorders (4th ed.). pp. 679681

(26) "Highlights of Changes from DSM-IV-TR to DSM-5" . American Psychiatric Association. 17 May 2013.

(27) "International Classification of Diseases (ICD)". World Health Organization. Retrieved 23 November 2010.

(28) "The switch from ICD-9 to ICD-10: When and why". Icd codes. Retrieved 19 January2018.

(29) Folkman, S., 2013. Stress: appraisal and coping. In Encyclopedia of behavioral medicine (pp. 1913-1915). Springer New York.

(30) Levo, Lynn M. (2003, September.) Understanding Defense Mechanisms. Lukenotes. 7(4). St. Luke Institute, MD.

(31)Raymond, EG; Grossman, D; Weaver, MA; Toti, S; Winikoff, B (November 2014). "Mortality of induced abortion, other outpatient surgical procedures and common activities in the United States". Contraception. 90 (5): 476-479.

(32) Chen, MJ; Creinin, MD (July 2015). "Mifepristone With Buccal Misoprostol for Medical Abortion: A Systematic Review". Obstetrics and Gynecology. 126 (1): 12-21.

(33) Bolton, Derek (2008). What is Mental Disorder?: An Essay in Philosophy, Science, and Values. OUP Oxford. p. 6. ISBN 9780198565925.

(34) Paltrow, Lynn M. (January 2013). "Roe v Wade and the New Jane Crow: Reproductive Rights in the Age of Mass Incarceration". American Journal of Public Health. pp. 17-21.

(35) Carlson, Bruce M.; Kantaputra, Piranit N. (2014). "4 Molecular Basis for Embryonic Development". Human embryology and developmental biology (5th ed.).

(36)Lois N. Magner (2005). History of the Life Science s. New York: Marcel Dekker. p. 166. ISBN 9780824743604.

(37) Cole, George; Frankowski, Stanislaw. Abortion and protection of the human fetus: legal problems in a crosscultural perspective, page 20 (1987)

(38) Journalist dies after attempting abortion, GhanaWeb, General News of Wednesday, 11 April 2018. https://www.ghanaweb.com//GhanaHomePage/NewsArchive/Journalist-dies-after-attempting-abortion642189

(39) Shah IH, Åhman E. Unsafe abortion differentials in 2008 by age and developing country region: high burden among young women. Reproductive Health Matters 6/2012;20(39):169-173.

(40)Definition of term pregnancy . Committee Opinion No 579 . American College of Obstetricians Gynecologists . Obstet Gynecol $2013122: 1139-40$

(41) Tagoe-Darko E. "Fear, Shame and Embarrassment": The Stigma Factor in Post Abortion Care at Komfo AnokyeTeaching Hospital, Kumasi, Ghana.

(42) Undercover In The Theater by Anas Aremeyaw Anas - Wild Ghana Project, September 2012. 